\title{
Sentidos y prácticas del poder: aproximación a las vivencias de jóvenes universitarios ${ }^{*}$
}

\author{
Ana María Arias Cardona** \\ José Andrés Soto Vélez $z^{* * *}$
}

\author{
Recibido: 10 de julio de 2016 \\ Evaluado: 16 de septiembre de 2016 \\ Aceptado: 4 de octubre de 2016
}

\section{Resumen}

Este artículo da cuenta de uno de los elementos analizados en la tesis doctoral sobre relaciones sociales ${ }^{1}$ en la Universidad; específicamente de la categoría "poder". La investigación se hizo bajo un diseño cualitativo, con un método hermenéutico, por medio de 14 talleres con técnicas interactivas y entrevistas a profundidad. Participaron 119 jóvenes (hombres y mujeres), matriculados en distintos pregrados de Ciencias Sociales y Educación, de universidades públicas y privadas (cuatro campus y seis sedes), ubicadas en el departamento de Antioquia (Colombia). El análisis de los resultados arrojó cuatro grandes subcategorías, cada una configurada según los relatos de los participantes; en este caso, se presenta el análisis de dos de ellas: "El poder asociado a la autoridad instituida: mantener el statu quo" y "El poder propio y la consciencia al respecto: tener más, ser más".

Palabras clave: jóvenes, universidad, poder.

Artículo de investigación científica basado en la tesis Relaciones sociales en la universidad: poder, conflicto y pluralidad entre jóvenes, presentada por la autora Ana María Arias Cardona, como requisito para optar al título de doctora en Ciencias Sociales: Niñez y Juventud. En el Centro de Estudios Avanzados en Niñez y Juventud de la Universidad de Manizales (CINDE). Proyecto aprobado por el Sistema de Investigación Lasallista (SIL), de la Corporación Universitaria Lasallista. DOl: http://dx.doi. org/10.15332/s1794-3841.2017.0028.06

** Psicóloga, especialista en Psicología Clínica, énfasis: Salud mental, magíster en Educación y Desarrollo Humano, Doctora en Ciencias Sociales: Niñez y Juventud. Fundación Centro Internacional de Educación y Desarrollo Humano - Universidad de Manizales. Docente tiempo parcial Corporación Universitaria Lasallista. Email: anamaria2468@gmail.com / anarias@lasallistadocentes.edu.co

*** Auxiliar de Investigación en GIPA (Grupo de Investigación en Psicología Aplicada) de la Corporación Universitaria Lasallista. Psicólogo de la Corporación Universitaria Lasallista - Caldas (Antioquia). Email: joseandres0823@hotmail.com

1 Relaciones sociales es una categoría muy amplia, configurada por muchos elementos que interactúan entre sí; pero para el caso de la tesis doctoral se trabajaron tres categorías: poder, conflicto y pluralidad. Este artículo se centra en la presentación de resultados sobre la categoría poder. 


\title{
Meanings and Practices of Power: Approach to the Experiences of University Students
}

\begin{abstract}
This article gives an account of one of the elements analyzed in the doctoral thesis on social relations in the University; specifically of the category "power". The research was done under a qualitative design, with a hermeneutic method; through 14 workshops with interactive techniques and in-depth interviews. 119 young people (men and women) enrolled in different undergraduate programs in Social Sciences and Education, from public and private universities (4 campuses and 6 venues), located in the department of Antioquia (Colombia). The analysis of the results yielded four major subcategories, each one configured according to the participants' reports; in this case the analysis of two of them is presented: "The power associated to the instituted authority: to maintain the status quo" and "The own power and the conscience on the matter: to have more, to be more".
\end{abstract}

Received: July 10, 2016

Evaluated: September 16, 2016 Accepted: October 4, 2016

Keywords: Young, university, power. 


\section{Sentidos e praticas do poder: aproximação às vivências dos jovens universitários}

\author{
Recebido: 10 de julho de 2016 \\ Avaliada: 16 de setembro de 2016
}

Aceito: 4 de outubro de 2016

\section{Resumo}

Este artigo da conta de um dos elementos analisados na tese doutoral sobre relações sociais 4 na Universidade; especificamente da categoria "poder". A pesquisa se fez sob um desenho qualitativo, com um método hermenêutico, por meio de 14 oficinas com técnicas interativas e entrevistas em profundidade. Participaram 119 jovens (homens e mulheres), matriculados em diferentes programas de graduação de Ciências Sociais e Educação, de universidades publicas e privadas (quatro campus e seis sedes), localizadas no departamento de Antioquia (Colômbia) A análise dos resultados mostrou quatro grandes subcategorias cada uma configurada segundo os relatos dos participantes; neste caso, apresenta-se a análise de duas delas: "O poder associado à autoridade instituída: manter o statu quo" e "O poder próprio e a consciência ao respeito: ter mais, ser mais".

Palavras-chave: Jovens, universidade, poder. 


\section{INTRODUCCIÓN}

Los seres humanos no son seres aislados, sino que están empujados, desde su propia naturaleza, al contacto con otros, y en ese acercamiento están llamados a entretejer relaciones sociales (Santillana, 2005, p. 227, Labourdette, 2007; Moyano, 2014; Herrera, 2000; PNUD, 2004), que se configuran de acuerdo con el contexto en el que brotan. Así, determinan el tipo de relación y las características que la componen; aunque con el tiempo estas pueden independizarse de dichos contextos, lo que implica un cambio en su naturaleza (Grossetti, 2014, p. 14).

En primer lugar, las relaciones sociales están integradas por numerosos elementos, lo que permite la comprensión de diversos mecanismos que se desplazan en la socialización. Uno de estos componentes es el poder, que si bien no es el único que puede explicar la forma como los seres humanos se relacionan, sí es fundamental a la hora de entenderlo (Piedra, 2004, p. 125).

No obstante, la noción de poder ha sido interpretada de varias formas, lo que da lugar a diversas representaciones, que se construyen de acuerdo con los discursos religiosos, políticos, económicos, académicos, etc., que dominan en un momento histórico; así, se esbozan las características que le imputan, y se señala quién o quiénes le detentan.

De este modo, existen nociones de poder que hacen referencia a un carácter negativo; por ejemplo, Meliá, Oliver y Tomás (1993, p. 140) lo conciben como capacidad de control e influencia sobre otros, por medio de la imposición de la propia voluntad. De igual forma, Duhart (2006, p. 31) considera que la potencialidad de influir en otros es la más fuerte manifestación del poder.

Así pues, para esta perspectiva, el poder necesariamente implica cierto tipo de relación en la cual el sujeto que lo posee logra alterar la posibilidad de emitir determinadas conductas en su objeto de influencia, y en su defecto, hace que lleve a cabo aquellas que él mismo desea (Meliá, et al. 1993, p. 140). Ahora bien, el objetivo de influir sobre el comportamiento de otros se logra, según Moreno (2006, p. 2), por medio de la violencia simbólica, en la que el agente garante de poder, por medio de la relación, impone a otro significados que son emitidos y recibidos como legítimos.

Sin embargo, para Duhart (2006, p. 31), el poder no debe comprenderse únicamente como relaciones de influencia o dominación, sino, también, de colaboración; ya que, de igual forma, puede ser entendido como la posibilidad de construir relaciones de cooperación mutua, desde el poder "con otros", y no en su dimensión conflictiva del poder "contra otros". De hecho, Anthony Giddens, citado en Duhart (2006, p. 33), nombra esta noción como capacidad transformadora o habilidad para lograr resultados en el trabajo mutuo.

De igual manera, Hannah Arendt (1970, pp. 41-43), citada en Múnera (2005, p. 36), percibe el poder como la capacidad humana de actuar colectivamente por consenso, puesto que las acciones llevadas a cabo conjuntamente le otorgan legitimidad al apoyo o a la obediencia de forma voluntaria dentro de determinado grupo social. Dicho de otra manera, el poder representa una capacidad para realizar una acción en conjunto, por medio del consenso con otros. 
En otro orden de ideas, Michael Foucault, citado en Piedra (2004, p. 133), entiende el poder como escenario que involucra a todo el cuerpo social, y lo desliga de la connotación tradicional en la que solo algunos miembros de la sociedad lo poseen; es decir, todos lo detentan de alguna $\mathrm{u}$ otra forma. Hay que destacar, también, que la perspectiva de Foucault sobre las relaciones de poder ha aportado significativamente a entenderlas desde la capacidad que tiene todo ser humano para ejercerlo; pues, según su idea, cada sujeto de la sociedad hace parte del tejido de relaciones de poder, no porque alguno le ostente, sino porque todos pueden participar de él; dado que se encuentra en todas partes (Foucault, 1998, p. 113, citado en Cano \& Arroyave, 2014, p. 99).

SegúnFoucault, el poder seencuentra en toda relación humana, en la medida en que los discursos, las instituciones, las normas y los valores que definen un contexto histórico específico permean la subjetividad, como herramienta de introyección de los discursos dominantes (Piedra, 2004, p. 125). Finalmente, hay que destacar que la propuesta foucaultiana es primordial para la presente investigación, ya que parte de la creencia de que todos los jóvenes universitarios ostentan el poder, sean o no conscientes de ello.

De acuerdo con estas ideas, son diversas las posturas y perspectivas que a lo largo del tiempo se han construido sobre la realidad del poder; sin embargo, se puede concluir que la mayoría de hipótesis están de acuerdo en que el poder es "una cualidad que atraviesa todas las relaciones sociales" (Bonvillani, 2010, p. 29).

Teniendo en cuenta que el poder ha sido ilustrado algunas veces de acuerdo con discursos políticos, religiosos y económicos, o influenciado por ciertos hechos históricos como las guerras, se ha hecho necesario para las ciencias sociales en las últimas décadas, según Herrera (2000, p. 39), encontrar un lenguaje científico que permita la comprensión de las relaciones y los componentes que la configuran; y abandonar la tendencia de atribuirle cualidades sin examinar el contexto relacional que permite su existencia. En otras palabras, el poder, como elemento de las relaciones sociales, siempre debe ser entendido desde los contextos en los que surge, y por consiguiente puede ser conceptualizado de numerosas formas, tantas como personas hay en la mundo.

Así pues, esta investigación pretende analizar las maneras en que los jóvenes vivencian, piensan y hablan sobre el poder presente en sus relaciones, partiendo del contexto en el que estas germinan; es decir, la universidad, un espacio para la socialización política entre jóvenes, en la cual se presentan diversos fenómenos de carácter social que le configuran como tal y le diferencian de otras áreas de socialización, como por ejemplo la discoteca, el concierto, el parque, etc.

De este modo, se busca identificar si fenómenos del contexto sociocultural de estos jóvenes, como el conflicto armado, la injusticia social, la desigualdad, el narcotráfico, la exclusión social, la violencia de género, permean cautelosamente los procesos de socialización en la universidad. Por ello, la investigación es un estudio crítico de la lectura que hacen los universitarios acerca del poder, en relación con asuntos socioculturales y expresiones idiosincráticas. 
De ahí que se parta de la hipótesis de que la forma como se representa el poder en un individuo en particular, que le permite diferenciarse de otro sujeto, tiene que ver con el tejido de las más diversas experiencias del individuo en su contexto social, al ponerse en contacto con lo religioso, económico, político, pedagógico, erótico, etc. (Santillana, 2005, p. 235). Además, se tiene en cuenta la idea de que todos estamos sumergidos en relaciones de poder, ya que lo ejercemos sobre otros y se ejerce sobre nosotros mismos (Piedra, 2004, p. 125).

Finalmente, se presentarán en el artículo los hallazgos de esta investigación frente a la categoría de poder, pero exponiendo únicamente dos de las cuatro perspectivas en las que fueron organizados los discursos de los participantes; así pues, primero se expone "El poder asociado a la autoridad instituida: mantener el statu quo", y finalmente "El poder propio y la consciencia al respecto: tener más, ser más".

\section{Materiales y Métodos}

La presente investigación responde a un diseño cualitativo, con el cual se busca vislumbrar la subjetividad de algunos jóvenes universitarios, de cara a la experiencia del poder, al identificar las construcciones que realizan por medio del lenguaje y por el lenguaje, con el fin de acceder a sus creaciones particulares de sentido (Luna, 2006, citada en Franco \& Roldán, 2015, p. 826).

En sintonía con la idea anterior, se puede aseverar que la característica propia del ser humano, y que le diferencia de otras especies, es el lenguaje y la capacidad de simbolización por medio de este. Por ello, la investigación cualitativa está diseñada para indagar el lenguaje y el habla de los sujetos participantes, ya que así se pueden llegar a explicar múltiples aspectos de la realidad, a partir de los discursos que son analizados e interpretados (Pérez, 2002, p. 374).

En este sentido, el enfoque epistemológico y el método más apropiado para facilitar el desarrollo del diseño cualitativo es el hermenéutico, porque, como medio metodológico en las ciencias sociales, permite abordar de manera consciente, en la palabra, las expresiones de quien narra, y así, dedicarse a la tarea del análisis de significados y sentidos que se encuentran en estas (Rojas, 2011, refiriéndose a Habermas, 2000).

Cabe añadir que, según Mieles, Tonon y Alvarado (2012, p. 203), la filosofía de la hermenéutica considera la comprensión como el terreno en el cual se desarrolla la experiencia humana; por esto, la comprensión de los discursos siempre debe hacerse desde los contextos que permiten su existencia, con el fin de evitar la pretensión de generalizar constantemente (Ángel \& Herrera, 2011).

En síntesis, la investigación cualitativa facilita un acercamiento a las voces de hombres y mujeres, en este caso universitarios, a través del lenguaje; mientras que la hermenéutica es un reconocimiento de los fenómenos humanos, por medio de la interpretación de sus discursos. Dicho de otra manera, con el diseño y enfoque de esta investigación se busca la aprehensión y comprensión de las relaciones sociales entre jóvenes universitarios, en relación con el poder.

Por otro lado, el trabajo de campo constó de 14 talleres con diversas técnicas interactivas 
(fotolenguaje, sociodrama, construcción de relatos, completación de frases y análisis de casos), en el que participaron 119 jóvenes (hombres y mujeres), de distintos pregrados de Ciencias Sociales y Educación, pertenecientes a las siguientes instituciones de educación superior (IES) del departamento de Antioquia (Colombia): Corporación Universitaria Lasallista, Universidad Cooperativa de Colombia, Politécnico Colombiano Jaime Isaza Cadavid y las sedes de la Universidad de Antioquia ubicadas en Medellín, Carmen de Viboral y Santa Fe de Antioquia. Las dos primeras IES son de carácter privado, y las dos últimas, instituciones públicas. Posteriormente, se seleccionaron 23 jóvenes para la realización de entrevistas en profundidad; estos representaban diversas opciones: religiosas, sexuales, políticas, etc.

También, se realizó un proceso de análisis de contenido que permitió organizar los datos construidos, hacer la tematización de estos, agruparlos por categorías y consolidarlos en subcategorías. En la tabla 1 se presentan dos de las cuatro subcategorías que se consolidaron, con base en los resultados de la categoría poder que se desarrolla en este artículo.

Tabla 1. Categoría poder

\begin{tabular}{|c|l|}
\hline \multirow{2}{*}{ Poder } & $\begin{array}{l}\text { El poder asociado con la autoridad } \\
\text { instituida: mantener el statu quo. }\end{array}$ \\
\cline { 2 - 2 } & $\begin{array}{l}\text { El poder propio y la consciencia al } \\
\text { respecto: tener más, ser más. }\end{array}$ \\
\hline
\end{tabular}

Fuente: Elaboración propia.

Finalmente, esta investigación siguió los lineamientos éticos establecidos en el Código Deontológico de Psicología (Ley 1090 de 2006), y lo que plantean distintos autores en investigación cualitativa. Se aplicaron los principios psicoéticos de beneficencia, justicia y autonomía; y las reglas de confidencialidad, veracidad-consentimiento válido y fidelidad a las promesas hechas, que propone França (2012).

\section{Resultados}

Para exponer el análisis de los resultados obtenidos, es preciso apuntar hacia la pregunta que guía la investigación; es decir, la interpelación por las formas en que circula el poder en las relaciones que establecen los jóvenes en la universidad. Dicho de otra manera, la tarea central de este apartado es poner el lente en el modo como los universitarios experimentan el poder en sus relaciones, en lo que concierne al "lugar que ocupa cada uno, la forma en que se toman decisiones y las funciones que cada uno desempeña en la relación" (Jaramillo, Arias, Arias, Restrepo \& Ruiz, 2012, p. 123).

Para empezar, es oportuno señalar que el concepto de poder que construyen los seres humanos, de acuerdo con Karlberg (2004, citado en Duhart, 2006, p. 31), se corresponde con el contexto sociocultural en el que se pronuncia; de esta manera, la idea contemporánea de poder se puede explicar por la trama sociocultural moderna, en la cual prima la cultura de la competencia, que imprime a la perfección las características del modelo de sociedad actual. Según el mismo autor, estos discursos modernos sobre el poder se han naturalizado a tal punto que la mayoría ni siquiera reflexiona sobre su practicidad, ya que se toma por sentado que siempre ha sido de esa forma.

En este caso, no se puede iniciar un análisis de los datos obtenidos, sin reconocer que las concepciones de poder expuestas por 
los participantes “están configuradas en un contexto de contemporaneidad y economía neoliberal" (Arias, 2017, p. 37-38), lo que hace que el discurso de los universitarios esté atravesado por los elementos que le caracterizan. Incluso, cabe examinar si el contexto sociocultural varía en su expresión, de acuerdo con el carácter privado o público, laico o confesional, de la universidad.

También es necesario tener en cuenta que el poder entre jóvenes universitarios no solo circula en medio de los fenómenos que ocurren en una clase, por ejemplo, con el trabajo en equipo, la discusión sobre un tema o la calificación que otorga el docente; sino que también se hace presente en medio de los escenarios informales, como la charla en la cafetería, el contacto a través de las redes sociales, la socialización en el pasillo (Arias, 2017 , p. 38). De ahí que para esta investigación se tenga en consideración el poder en ambos escenarios.

Por otro lado, la forma como ciertos autores se han inclinado a estudiar la cuestión del poder se puede sintetizar al señalar que algunos lo han explorado desde su carácter vertical, al ubicar por encima a quien lo posee (Ávila, 2008); otros se han dedicado a estudiarlo, tanto en su representación individual como social (Penaglia, 2012); algunos otros orientan sus reflexiones en el modo como se mueve en las instituciones (García, 2009); otros tantos indagan sobre el poder como la influencia en terceros, tanto en cuanto permite crear y hacer, o, por el contrario, como obstáculo (Montero, 2010; Labourdette, 2005); y también se cuentan aquellos que escudriñan su capacidad cooperativa para actuar en consenso con otros (Duhart, 2006; Serrano \& López, 1994).
En este sentido, cabe destacar que la perspectiva que se configura como punto de partida y es transversal a toda la investigación es el análisis que realiza Michael Foucault sobre las relaciones de poder; según el autor, es preciso tener en cuenta lo siguiente: "[...] el poder, si no se lo contempla desde demasiado lejos, no es algo dividido entre los que lo poseen, los que lo detentan exclusivamente y los que no lo tienen y lo soportan [...]" (Foucault, 1976, p. 74).

Lo anterior significa que todo ser humano ostenta poder, incluso si no es consciente de ello (Arias, 2017, p. 37); por lo tanto, el poder no es una parcela que se compre, se negocie, se intercambie o le pertenezca a alguien en particular, sino que circula en todas las relaciones humanas. Tanto así, que desde hace unas décadas las ciencias sociales conciben el poder como una relación (Piedra, 2004, p. 123). Ejemplo de esto es la expresión de uno de los jóvenes participantes de una de las universidades públicas: "[...] el poder sería como algo intrínseco, algo que tiene que estar ahí, no como algo necesario, sino como algo que obligatoriamente se va a dar, porque las relaciones se establecen así" (expresión recolectada en una de las plenarias).

Del mismo modo, Foucault libera la noción de poder de la tendencia a polarizarla en unas cuantas personas de la sociedad y de la visión reducida de algunas hipótesis, en que se le ve únicamente desde el ejercicio del reprimir o influenciar a otros. Foucault hace mención a este tema cuando afirma: "[...] si el poder no tuviese por función más que reprimir, si no trabajase más que según el modo de censura, de la exclusión, de los obstáculos, de la represión, a la manera de un gran superego, si no se ejerciese más que 
de una forma negativa, sería muy frágil. Si es fuerte, es debido a que produce efectos positivos a nivel del deseo y también a nivel del saber" (Foucault, 1996, p. 107).

Esto quiere decir que para Foucault el poder no debe ser entendido como bueno o malo, sino como realidad inevitable a toda relación social (Foucault, 1972, p.107; Serrano \& López, 1994, p.178; Montbrund, 2010, p. 385). De este modo, la investigación se acerca libre de prejuicios e ideas preconcebidas acerca de la forma como los jóvenes universitarios pueden representar el poder en sus relaciones, con el fin de aprehender su subjetividad.

Ahora bien, los resultados que arrojaron las técnicas de recolección de datos se organizaron por categorías y subcategorías, para posteriormente ser analizadas. Se puede señalar, inicialmente, que una característica transversal a toda la categoría macro fue la manifestación del componente inconsciente y simbólico del poder propio, ya que cuando se les indaga sobre "su" poder, tienden a no identificar el ejercicio que hacen de este, mientras que sus narraciones hacen mucho énfasis en las figuras externas, que, según ellos, lo ejercen como "acto concreto, consciente y arbitrario" (Arias, 2017, p. 38).

Los hallazgos frente a esta categoría pueden analizarse desde cuatro perspectivas: 1 . el poder asociado con la autoridad instituida, como un mecanismo para mantener el statu quo; 2. el poder propio y la consciencia al respecto, que implica que "tener más" suele verse reflejado en "ser más"; 3. el poder como asimetría inevitable, que da cuenta de la perpetuación de abusos; 4 . las prácticas de resistencia como intentos de revertir lo instituido. A continuación se abarcan, específicamente, los resultados de las dos primeras.

\section{El poder asociado con la autoridad instituida: mantener el statu quo}

Antes de profundizar en la manera como los participantes de esta investigación perciben el poder como mecanismo para mantener el orden dentro la universidad, hay que señalar primero a quienes ellos identifican como sujetos que detentan poder en el contexto universitario. En este sentido, los jóvenes participantes están de acuerdo en que la institución, los docentes y ellos mismos ostentan poder, aunque, según sus relatos, este pareciese tener siempre un uso negativo.

Ahora bien, cada uno de estos tres personajes es revestido de un carácter particular respecto al modo como usan o abusan del poder. De este modo, y en coherencia con lo relatado por los universitarios, se separa cada personaje en una subcategoría para poder desarrollar el análisis apropiado (las subcategorías se presentan más adelante).

Primero que todo, hay que examinar cómo puede ser entendido el statu quo. Por ejemplo, Jiménez (2013) considera que para Weber (1984), el statu quo se refiere a "un orden social consensuado específico; un 'modelo' de relaciones sociales que 'orienta' la acción" (p. 45). Esto quiere decir que el statu $q u o$ es sinónimo de orden social, construido de forma inconsciente por las personas por medio de su consentimiento, donde el modelo que se presenta de sociedad es aceptado como forma de organizarse socialmente para alcanzar unos fines. 
En lo que se refiere al poder en relación con el statu quo, se expone de una manera muy concisa y gráfica la expresión de un joven estudiante de universidad privada, cuando señala que las personas en relación con el poder tienden a "ser como los animales", dado que de la misma forma como el animal más fuerte (nótese que esta es la característica que le hace ostentar poder) mantiene organizada la manada, en el ser humano el más fuerte ejerce su poder sobre los más débiles, para mantener el orden establecido.

Es así como los participantes perciben en las relaciones que surgen dentro del contexto universitario, "la necesidad de regular los vínculos y de perpetuar así un orden establecido" (Arias, 2017, p. 41), al asociar la tarea de mantener el orden con una autoridad instituida, que encarnan los adultos (como figura formal de la institución) o algunos de sus pares; poseedores, según los participantes, de algunas características hegemónicas, que son las que le otorgan poder, como ser hombre, heterosexual, católico, mestizo.

Martínez, Paterna y Angosto (2000) explican este asunto desde la teoría de la dominancia social; así, están de acuerdo en que las sociedades siempre se organizan desde el principio de ordenación jerárquica, según la cual, los grupos que se establecen como dominantes saborean privilegios y ostentan el poder, mientras que los subordinados carecen de estos.

En definitiva, pareciera que las narrativas de los participantes respaldan las nociones negativas del poder como verticalidad, abuso y exclusión; pero proyectado en lo externo, dado que casi ningún joven se reconoce como sujeto capaz de detentar el poder o de abusar de este. Se prosigue, entonces, a profundizar en los relatos de los universitarios, de acuerdo con los personajes que ostentan el poder para mantener el statu quo.

\subsection{La institución que abusa: la universidad como "ente" deshumanizado}

Ante todo, vale la pena decir que las decisiones institucionales son percibidas, por los participantes de la investigación, como injustas y verticales; dada su condición impositiva e inamovible, dictaminada por los directivos y docentes. Dicha inconformidad es reiterada por la mayoría de los participantes, mediante la técnica de completación de frases, como lo ejemplifica el siguiente fragmento: "el poder en la universidad... 'es imposición y manejo burocrático'; 'se puede observar todos los días y en todos los lugares'; 'no está bien ejecutado, es un poder con poco impacto'; 'se liga con las influencias, beneficios y oportunidades'."

En efecto, los relatos de los jóvenes universitarios dejan entrever una marcada molestia hacia las normas impuestas por la institución, que les deja la sensación de ser tomadas unilateralmente y solo con intereses administrativos, como el pago de la matrícula, el uso del parqueadero o el cobro de certificados.

De igual forma, es característico en el discurso de los participantes, la predisposición a pensar que la propia universidad es más abusadora que las otras, e incluso poniendo el acento en el carácter privado o público de esta. Así, la universidad, pero en especial la privada, es percibida por los jóvenes como una institución con intereses personales, en la que pareciese que la preocupación 
más importante es aumentar su capital; tal como lo muestra uno de los fragmentos de las técnicas de completación de frases $y$ de la construcción de relatos realizados en las distintas universidades, el estudiante escribe: "El poder en la universidad lo tienen los directivos que hacen las normas a su antojo para el bien de ellos, únicamente $\$ \$ \$ \$ "$.

De este modo, los jóvenes de universidades privadas que participaron en la investigación señalan la existencia de un fenómeno presente en torno al valor de las matrículas frente a los servicios que ellos obtienen como estudiantes; por ejemplo, respecto al uso de espacios como auditorios, conectividad a internet, calidad de las aulas, etc. Justifican que quienes reciben los mejores servicios y trato por parte de la institución son aquellos que pagan un valor más alto en sus matrículas.

No obstante, los estudiantes de instituciones públicas, desde su imaginario, visualizan que en la universidad privada sus estudiantes gozan de mayores beneficios y privilegios, explicado por el costo tan alto de sus matrículas; es decir, por su condición de "clientes" (Arias, 2017, p. 44). Por el contrario, los jóvenes de universidades privadas piensan que, como su institución solo se interesa por lo económico, si estuviesen en una universidad pública se les valoraría realmente como estudiantes y se les tendría en cuenta para la toma de decisiones. Así pues, exponen que en las instituciones de carácter público "se dan prácticas más democráticas y horizontales".

Lo anterior coincide con los planteamientos de Murcia (2008), cuando afirma que: "son muchas las luchas que deben librar los jóvenes y las jóvenes para que en la vida universitaria sean tomados y tomadas medianamente en serio dentro de sus estructuras" (p. 14).

Por otro lado, los jóvenes universitarios evalúan a los directivos y docentes como figuras que ostentan poder; así, cuestionan sus formas de proceder laboralmente y la postura que asumen a la hora de tomar decisiones que les afectan como estudiantes. Esta situación puede ser expuesta con los siguientes fragmentos de las técnicas de completación de frases y de la construcción de relatos realizados en las distintas universidades: "El poder en la universidad se visualiza en la imposición del docente", "Dentro de ese edificio [la universidad] algunos hablaban y otros obedecían".

En síntesis, para los universitarios, tanto de universidad pública como privada, su experiencia está atravesada por la sensación de ser victimizados, ultrajados y deshumanizados por la institución a la cual se encuentran matriculados.

\subsection{El rol docente frente al poder: del saber como ventaja y de la calificación como instrumento}

Según Foucault (1976, citado en Arias, 2017): "El poder, lejos de estorbar al saber, lo produce" (p. 45). Este argumento del autor puede entrar a conversar con lo relatado por los jóvenes que participaron en esta investigación, ya que en sus percepciones sobre la relación saber-poder, ambos suelen estar asociados con la posición que toman los estudiantes en no cuestionar las ideas o argumentos de quien identifican con un alto grado de conocimiento. 
Así pues, la autoridad intelectual es comprendida por los participantes como otra forma en que la institución hace uso de su poder desde la verticalidad; es decir, desde la imposición del saber. De hecho, Foucault aporta más elementos en su análisis para la comprensión de esta relación saber-poder: "Estas relaciones de poder no pueden disociarse, ni establecerse, ni funcionar sin una producción, una acumulación, una circulación, un funcionamiento del discurso. No hay ejercicio de poder posible sin una cierta economía de los discursos de verdad [...]" (Foucault, 1996, p. 147-148).

En este orden de ideas, surge en las voces de los universitarios la calificación como instrumento del docente para posicionar su saber como verdad, lo que les hace sentir que el dominio lo tienen ellos y no los estudiantes. Es importante señalar que los participantes parecen no tener claro la diferencia entre la evaluación y la calificación impartida por el docente, es decir, si bien en la evaluación el docente realiza un juicio del proceso formativo del alumno en pro de avances o retrocesos, los estudiantes no perciben en la labor del docente esa actitud, mientras que sí hacen referencia a la calificación como instrumento para ser valorados numéricamente, incluso, basándose en asuntos personales y no solo académicos; lo cual es interpretado como abuso de poder. Esto se puede ejemplificar en la voz de una participante: "Yo sé que una vez pasó que uno de ellos no sacó 5 , y casi todo el salón había sacado 5 y él le hizo el reclamo a la profesora y ella le dijo que: por no tener la capacidad de perder, le ponía un 3, pues, le rebajó antes la nota [...]" (entrevista a mujer, estudiante de universidad privada).
De igual forma, la nota es vista como expresión del tipo de vínculo afectivo que tiene el docente con el grupo o la preferencia hacia un estudiante; por ejemplo, cuando la usa para castigar al grupo por comportamientos que no aprueba. Por tanto, la evaluación se piensa como una estrategia para abusar del poder. Además, los docentes son percibidos por sus estudiantes como autoritarios e inflexibles, y equiparan su rol con quien da instrucciones, que, según los universitarios, no se ponen a la mesa para ser discutidas, y frente a las cuales aquellos no suelen ceder.

Para ilustrar las percepciones de los participantes ya mencionadas, se puede acudir a los hallazgos de Álvarez, Díaz y Vergara, quienes afirman lo siguiente: "Al analizar los textos significativos de los docentes, se observa desde su discurso, un predominio de justificaciones morales tendientes a mantener el orden, mediante la norma y el reglamento, como único recurso y frecuentemente bajo la forma de castigo, sanción o exclusión" (2006, p. 79).

En otras palabras, el uso del poder que hacen los docentes, expresado en las acciones (calificación, evaluación, autoritarismo), señaladas por los participantes de la investigación, pueden ser leídas como mecanismo e instrumento para mantener el statu quo dentro del aula y en la institución.

Sin embargo, en la narrativa de algunos participantes surge cierta referencia a usos positivos del poder en relación con el saber, ya que han experimentado que algunos docentes ponen al servicio de los estudiantes su propio saber. En palabras de un participante: "los profesores que son también como los que tienen el conocimiento, 
entonces ellos incluso prestan ayuda, incluso dicen: mándeme un correo o escríbame al WhatsApp, todo eso, ellos prestan la ayuda" (fragmento de entrevista a hombre de universidad privada).

Esto podría entenderse desde lo que Soledad (2012) denomina como "autoridad carismática", que se manifiesta en la capacidad altruista del docente, llevada a cabo por medio de la escucha, los consejos y la ayuda académica.

\subsection{La actitud de estudiantes frente al poder: entre la sumisión, la pasividad y el resentimiento}

A continuación se presentan tres actitudes específicas en relación con el uso del poder, asumidas frecuentemente por los estudiantes. Así pues, en sus relatos se identificaron las posiciones sumisa, pasiva y resentida.

La actitud sumisa suele aparecer en situaciones del contexto universitario en las que no se desea luchar, sino que, por el contrario, se obedece dócilmente para evitar consecuencias negativas, pues según algunos participantes, en ciertos escenarios se "llevan las de perder": "Entonces aquí hay profesores, por ejemplo, que les tiene miedo todo mundo, y no... ese man es muy buen profesor, es un psicólogo el hijueputa, es una eminencia, que tal yo llevarle la contraria... ¡inooo!!” (fragmento de entrevista a hombre, estudiante de universidad privada). En este sentido, algunos estudiantes, frente al rol del docente, asumen una posición de retirada, dada su creencia de que su lucha como estudiante siempre será en vano.
Igualmente, la posición pasiva se manifiesta en la no participación de los estudiantes, según ellos, por pereza y facilismo, puesto que es mejor dejar que otros lo hagan, y no salirse de su zona de confort. De hecho, los mismos participantes analizaron sus ideas y relacionaron su pasividad con actitudes propias, asociadas con el "egoísmo, el individualismo y la comodidad" (Arias, 2017, p. 50).

En relación con el resentimiento, se hace evidente en el discurso de los participantes la sensación de estar siendo abusados y silenciados por la institución, asunto que perciben como injusto, dada su condición de clientes (expresión más marcada en los estudiantes de universidad privada), según la cual, por lo tanto, tendrían derecho a exigir.

Vale la pena retomar las ideas de Álvarez (2012) para entender la presencia de estas tres posturas en la forma como conciben el poder los estudiantes: "El poder implica la capacidad de hacer algo pero también negarse a hacerlo, contiene las posibles implicaciones de dominar, obligar, persuadir y también de liberar" (p. 29).

Lo anterior hace surgir la necesidad de que las universidades reflexionen sobre asuntos como este, pues suponen nuevos retos en los procesos de socialización política, que finalmente pueden resultar en la formación de estudiantes con capacidad crítica frente a su rol y responsabilidad en los diferentes escenarios que se presentan en el contexto universitario; todo ello, con el fin de obtener su participación y evitar que continúen senalando a otros como culpables de las cuestiones que les resultan molestas. 


\section{El poder propio y la conciencia al respecto: tener más, ser más}

Inicialmente, cabe resaltar que en la subcategoría anterior se hizo más énfasis en cómo los jóvenes universitarios proyectan en agentes externos la capacidad de ostentar poder; figuras que, desde su pensar, abusan de autoridad e influencia, por su rol como directivos y docentes. Ahora bien, en esta subcategoría se analizan asuntos que salieron a relucir en los relatos de los participantes, los cuales dirigen el poder ya no hacia otros, sino hacia ellos mismos.

De este modo, en las diferentes técnicas de recolección de datos se expusieron ideas sobre características personales que a los estudiantes les confiere poder, y cuyo uso implica aspectos positivos y negativos. Así lo permite ver un joven en la situación que plantea: "sí, el poder es importante, no en la dimensión de manejar a los otros como marionetas, sino en usted reconocer sus propias capacidades, es que usted puede" (fragmento de entrevista a hombre, estudiante de universidad privada).

\subsection{Características propias como ventajas para "poder"}

Al indagar en los jóvenes universitarios sobre el poder propio, se presentó reiterativamente el señalamiento de características que ellos mismos califican como el punto de partida para detentar poder. De este modo, los universitarios consideran que entre ellos quienes detentan poder son los que "tienen más" dinero, conocimiento, belleza, capacidad de influencia, etc. En otras palabras, apuntan hacia aquellos que a manera de ventaja poseen estos rasgos particulares para hacer uso o abuso de su poder.
Otras características que fueron expresadas por los participantes, pero que no tuvieron tanta fuerza en sus relatos, son el poder relacionado con el "ser mayor en edad", dado que esto genera más respeto; "hablar más", explicado en su persuasión y convencimiento; "liderazgo", puesto que se cuenta con el valor para tomar la iniciativa y dirigir a otros; y finalmente, "hacer parte de la mayoría", pues se goza de aceptación social y apoyo a la hora de tomar decisiones.

Lo expuesto hasta el momento se puede ejemplificar con las palabras de un participante: "Entre estudiantes se presenta el poder, como te digo, por el conocimiento, por la capacidad económica, de las ideas, de los argumentos también, el que puede es el que puede argumentar, sea con ideas o con plata" (fragmento de entrevista a hombre, estudiante de universidad privada. Se eligió por ser líder, representante de grupo).

Según el estudio, la referencia que hacen los participantes del conocimiento como rasgo de quienes poseen poder en la universidad se corresponde con una tendencia de estos a buscar reconocimiento en el grupo, a querer figurar como importantes entre sus pares y a la satisfacción de una necesidad de seguridad, que le confiere el saber más sobre un tema determinado.

Es decir, los participantes se perciben con poder cuando su grado de inteligencia les concede la categoría de ser un estudiante destacado, y esto a su vez les ubica en un lugar de superioridad y reputación frente a quienes no están a su altura; sentimientos que son valorados por los participantes como positivos, ya que parece agradarles ser el centro de atención y obtener reconocimiento. El siguiente fragmento, obtenido 
con la técnica de construcción de relatos, ilustra la idea del conocimiento como poder y sus efectos: "[...] fue ganando la reputación del chico más inteligente, cosa que era muy agradable para él, [...], con el paso de los meses sentía que era indispensable para sus compañeros y se volvió arrogante $\mathrm{y}$ egoísta, ya no quería compartir su conocimiento y empezó a excluir a aquellos que menos sabían por este simple hecho [...]".

En lo que respecta al tema de quienes tienen más dinero, los participantes refirieron que aquellos obtienen el poder al exhibirse y ostentar su capacidad de compra y consumo de bienes; es decir, se ubican en un lugar de poder cuando dejan entrever entre sus pares el propio poder económico. Este fenómeno se torna grupal cuando se convierte en una excusa para rendir pleitesía a quienes tienen más dinero. En palabras de una estudiante: "más que todo las personas que yo he visto que tienen como dinero empiezan a hablar: es que no, es que yo fui pa' tal parte, es que yo me gasté tanto, y muestran los celulares, muestran las cosas de marca, es que me compré esto y me compré lo otro" (fragmento de entrevista a mujer, de universidad privada).

Por otro lado, la belleza fue otra de las características que los participantes enfatizaron en sus relatos sobre los modos de hacer uso o abuso del poder. Según ellos, quienes poseen atractivos físicos, de acuerdo con los estereotipos sociales, poseen capacidad de influencia sobre otros, tienen beneficios académicos y gozan de la admiración de sus compañeros.

En este sentido, Martín (2002) opina que lo que construimos socialmente bajo la categoría de belleza no es más que un aprendizaje logrado por medio de hábitos, conocimientos y experiencias, tanto individuales como sociales, que orientan nuestros juicios de lo estético, y se constituyen a favor y en forma de poder de quienes encajan en estos criterios. Lo anterior puede ser ejemplificado por el relato de un joven: "[...] las chicas que por lo general dice uno: 'se visten muy mostronas', por así decirlo, siempre las atienden, las tratan como..., pues que no vienen a la universidad a hacer lo que deben ser, como que de pronto, que por el cuerpo van a ganar la materia..." (fragmento de entrevista a hombre, en formación religiosa, proveniente de la zona Caribe colombiana).

Este señalamiento a la belleza se hace con mayor fuerza cuando se menciona al género femenino; sin embargo, también se hace alusión a cómo los hombres ostentan poder en favor de su aspecto físico. De este modo, la relación belleza-poder parece estar también asociada con favores sexuales para beneficio académico, dado el poder que allí circula; tal como lo manifestó un participante: "Pues es que eso acá no es solo para las chicas, también es para los hombres inclusive, en profesores también. Sí, eso hay quien compra la materia, no tiene nada que ver si es mujer o no" (fragmento de entrevista a hombre, estudiante de universidad privada).

De este modo, los participantes hicieron eco sobre la forma en que una característica como la belleza se vuelve un arma para alcanzar sus intereses personales, por medio del uso de su sexualidad con aquellos de quienes desean obtener algo. Este asunto pareciese ser naturalizado en el contexto universitario, y es interesante poder abordarlo en estudios posteriores sobre el género-poder. 


\section{2. "El poder saca lo mejor y lo peor de} cada uno"

En este caso, el poder toma en la subjetividad de los participantes dos aspectos que se polarizan el uno al otro; es decir, la conciencia de que el poder propio se puede manifestar tanto de manera positiva como negativa. Esto puede visualizarse en uno de los fragmentos del debate de un taller en una universidad privada, en el que se implementó la técnica de fotolenguaje: “[...] cuando hay poder, el corazón nos define tal y como somos, porque el poder nos da unos rasgos positivos, unos rasgos negativos... Saca lo bueno, saca lo malo, hay líder positivo, hay líder negativo $[\ldots] "$.

De este modo, las voces de los jóvenes universitarios describen algunos aspectos positivos del poder, como la defensa de los derechos propios y ajenos, la capacidad para expresar oposición cuando no se está de acuerdo, la participación activa, reconocer las propias capacidades, la toma de decisiones y liderazgo.

Respecto al liderazgo como aspecto positivo del poder, en las narrativas de los universitarios se hicieron visibles dos tipos de líderes: uno externo al grupo y otro que surge en su interior (Barra, 1998). Ambos gozan de influencia y capacidad propositiva, ante la cual los estudiantes tienen la posibilidad de tomar la decisión de aceptar o rechazar la propuesta. Esto se ilustra en el siguiente relato: "Ella tenía el liderazgo, ella hablaba, nos proponía y nosotros aceptábamos o no aceptábamos" (fragmento de entrevista a mujer rural, estudiante de universidad pública).
Por otro lado, también se hizo énfasis en los aspectos desfavorables del poder propio, como la habilidad para manipular y obtener lo que se quiere; la imposición de la propia voluntad; la capacidad de cambiar decisiones por medio de las influencias que se tienen; poner los intereses propios por delante de los ajenos; la ayuda aparentemente "desinteresada" como mecanismo para después crear necesidad en los otros, etc. En otras palabras, el poder puede volverse pervertido y patológico (Arias, 2017, p. 57).

Finalmente, las ideas expuestas sobre esos aspectos positivos o negativos del poder son nombradas así en uno de los fragmentos del debate, en un taller en una universidad privada en el que se implementó la técnica de fotolenguaje: "[...] el poder es un instrumento que es bueno, lo que pasa es que el ser humano no lo sabe utilizar. Entonces digamos que un cuchillo no es malo, si no lo utilizas para matar a una persona $[\ldots]$...

\section{Discusión Y CONCLUSIóN}

Atendiendo a estas consideraciones, expresadas en los resultados de la investigación y analizadas en estas subcategorías que se acaban de exponer, se abre paso a la discusión sobre aquellos asuntos que merecen un análisis más a fondo y el apunte de algunas cuestiones que necesitan ser abarcadas en posteriores investigaciones, ya que en esta exploración quedan como asuntos aún por profundizar, o crean una sana tensión entre lo que presenta la teoría y lo que nombraron los universitarios.

Inicialmente, se hace ineludible reflexionar sobre ese asunto de mantener el statu quo, puesto que los participantes 
responsabilizaron a la institución, encarnada por directivos y docentes, por el abuso del poder como instrumento para mantener el orden institucional, y alejaron de sí mismos toda responsabilidad en la perpetuación de lo concebido como modelo institucional.

En este sentido, según Solano (2010, p. 38), la universidad se configura como institución al servicio de la sociedad, que se apoya en la permanencia de un orden social y perpetúa las formas organizativas establecidas en este, a la vez que proporciona medios de renovación. Sin embargo, los medios de renovación de los que habla el autor no son expresados por la gran mayoría de los participantes de esta investigación, sino que sus relatos apuntan constantemente a quejas y denuncias sobre la conservación del orden preestablecido por medio de mecanismos institucionales que califican como arbitrarios.

Así pues, la noción del poder en relación con la preservación del statu quo universitario resulta un desafío para la institución misma, considerada como escenario de socialización política, puesto que debe reflexionar en torno a cómo suscitar en sus estudiantes subjetividades críticas y reflexivas, que generen empoderamiento desde la vida en común y el interés por lo social (Arias \& Pachón, 2015, citado en Arias, 2017, p. 41).

Por otro lado, la "investidura de autoridad" (Santillana, 2005, p. 232) del docente, no solo en relación con el conocimiento, genera una alta tensión en asuntos como la evaluación-calificación, por la influencia que puede tener en este el vínculo que teje con sus estudiantes; pero llama la atención que en los relatos de los participantes no haya ejemplos explícitos que señalen alguna actitud por parte del docente hacia los estudiantes que les impidiera expresarse o debatir sus ideas. Sería importante indagar qué experiencias o imaginarios respaldan dichas ideas (Arias, 2017, p. 45).

Ahora bien, también cabe pensar en otro asunto que en los resultados deja la sensación de ser un punto ciego en la subjetividad de los participantes, pues al interrogar sobre quiénes detentan poder en la universidad, tienden a señalar al otro y no tocan el tema del poder propio; en efecto, porque se conciben como individuos abusados por un tercero, pero casi ninguno reconoce en sí mismo la posibilidad, no solo de ostentar poder, sino, además, de abusar de él, o de facilitar el crecimiento social por medio del uso del poder propio. Este fenómeno puede ser nombrado como externalización del poder, y es un asunto interesante para profundizar en futuras investigaciones, e incluso vale la pena reflexionar al respecto, tanto en el aula como fuera de ella.

De igual modo, sobresalió mucho la idea de ciertas características personales en relación con poseer la capacidad de influir sobre la voluntad de otros (en dos palabras, detentar poder) (Cialdini, 1994), ya que en ocasiones son elementos que se presentan en el plano de lo inconsciente y espontáneo. Aunque es muy significativo que para la mayoría de los participantes estas características sean como una especie de dotación genética que les permite ostentar poder; es decir, elementos que se reúnen en una persona y se conforman de tal manera que estas pueden, casi naturalmente, hacer que los demás giren en torno suyo (Arias, 2017, p. 56).

Respecto al poder asumido como propio, llama la atención que los estudiantes, 
hombres y mujeres, argumentan en sus relatos individuales el uso del poder propio justamente desde aquello que cuestionan y condenan de la institucionalidad, e incluso del capitalismo. Es necesario reflexionar sobre este asunto en los espacios que brinda la universidad para la formación humana de sus estudiantes.

Otro de los retos que se plantea es profundizar en las diferencias del poder según el género, ya que los jóvenes universitarios reconocen que tanto hombres como mujeres detentan poder, pero no mencionan cómo es el uso en cada uno de ellos (Piedra, 2004). Aunque se hace referencia a ciertas características de la persona que le confieren cierto grado de poder, por ejemplo, el liderazgo o la capacidad de expresarse, hace falta la comprensión de cómo el ser hombre o mujer genera movimientos de influencia o liderazgo con sus pares.

Además, el tema de las tecnologías de la información y la comunicación (TIC) no tuvo mucha fuerza en las expresiones que proporcionaron los participantes, pero es una realidad social que los atraviesa $\mathrm{y}$, por lo tanto, un espacio para el intercambio de poder. Cabe la posibilidad de que quizá ellos como estudiantes no asocien directamente el poder con las TIC. Es necesario, entonces, ahondar sobre este asunto en próximos estudios.

Se propone igualmente contrastar estos resultados con otros de estudiantes que no cursen carreras de las ciencias sociales, sino que pertenezcan a otras áreas de conocimiento, con la finalidad de no proporcionar una mirada sesgada de este asunto.
Para la universidad como institución y lugar de socialización entre jóvenes, independientemente de si es pública o privada, laica o católica, rural o urbana, este análisis le sirve para la reflexión acerca de su papel como facilitadora de espacios para que los universitarios se piensen respecto a sujetos inmersos en relaciones de poder, e incluso para que la misma universidad (encarnada, según los participantes, en los directivos y profesores) se piense a sí misma como entidad que detenta poder, y se cuestione sobre cómo lo usa.

Se presenta, entonces, la propuesta a las universidades para que fortalezcan asuntos en sus estudiantes, como el reconocimiento del poder propio y su uso, considerando elementos como el género, la diversidad cultural, las características personales y el contexto sociohistórico; también, el no tener miedo de generar participación política juvenil, por medio de los mecanismos de resistencia no violenta ante aquellos asuntos que para los universitarios se alejan de sus necesidades, y además, la búsqueda de su bienestar personal y colectivo.

El poder es uno de esos componentes del entramado social que surge en el contacto con el otro; en este sentido, la universidad es un terreno fértil, en el que germina la interacción social y, por consiguiente, el poder, como característica inherente a aquella. Asunto que es confirmado y aceptado por los estudiantes.

Igualmente, en sus discursos emerge el poder como una capacidad de la que se dispone o de la que se carece, y como la oportunidad para generar cambios a escalas micro y macro. Sin embargo, su visión tiende a ser 
negativa, desconociendo su cualidad propositiva y creativa.

En general, las investigaciones que se han realizado en esta misma vía se encuentran más asociadas en términos de educación básica y media, mas no en educación superior, dado que en esta última se presenta como autonomía universitaria. En otras palabras, en educación superior no hay elementos específicos del currículo de estudios que den cuenta de esto, mientras que en básica y media sí hay lineamientos del Ministerio de Educación.

Para concluir, las universidades tienen descuidados aspectos relacionados con la sociabilidad política; si bien algunas tienen en sus planes de estudio asignaturas relacionadas con formación humana, a veces los estudiantes las ven como un relleno y no como una propuesta formativa.

\section{REFERENCIAS}

Álvarez, A. (2012). Las prácticas de crianza en primera infancia como tecnologías de poder en el contexto familiar y en el contexto educativo (tesis de maestría). Universidad de Manizales-CINDE, Manizales. Recuperado de http://ridum. umanizales.edu.co:8080/jspui/bitstream/6789/237/1/401_Alvarez_Maestre_Annie_Julieth_2012.pdf

Álvarez, L., Díaz, P., \& Vergara, A. (2006). Justificaciones morales del docente (tesis de maestría). Universidad de Manizales CINDE, Manizales.

Arias, A., \& Pachón, M. (2015). Ética en jóvenes: norma, empatía y sentido de justicia en estudiantes de educación superior. En Retos y realidades de la Psicología educativa. Memorias del Congreso Nacional de Psicología Educativa (ASCOFAPSI). Caldas: Editorial Lasallista.

Ángel, D., \& Herrera, J. (2011). La propuesta hermenéutica como crítica y como criterio del problema del método. Estudios filosóficos, 43, 9-29.

Arias, A. (2017). Relaciones sociales en la universidad: poder, conflicto y pluralidad entre jóvenes (tesis doctoral inédita). Centro de Estudios Avanzados en Niñez y Juventud de la Universidad De Manizales - CINDE.

Ávila, F. (2008). El concepto de poder en Ernesto Mayz-Vallenilla. Revista de Ciencias Sociales, 14(3), 635-650.

Barra, E. (1998). Psicología social. Chile: Universidad de Concepción. Recuperado de http://www.sibudec.cl/ebook/ UDEC_Psicologia_Social.pdf

Bonvillani, A. (2010). Jóvenes cordobeses: una cartografía de su emocionalidad política. Nómadas, (32), 27-44.

Cano, T., \& Arroyave, O. (2014). Procesos de empoderamiento de mujeres: subjetivación y transformaciones en las relaciones de poder. Revista Virtual Universidad Católica del Norte, 42, 94-110.

Cialdini, R. (1994). Influence: The psychology of persuasion. New York: Quill.

Duhart, D. (2006). Exclusión, poder y relaciones sociales. Revista Mad. Revista del Magíster en Análisis Sistémico Aplicado a la Sociedad, (14), 26-39.

Foucault, M. (1972). Historia de la sexualidad. México: Siglo XXI.

Foucault, M. (1976). Vigilar y castigar. México: Siglo XXI, México

Foucault, M. (1996). Microfísica del poder. Madrid: Editorial de la Piqueta.

Franco, Á., \& Roldán, O. (2015). Sentido de la responsabilidad con la salud: 
perspectiva de sujetos que reivindican este derecho. Revista Latinoamericana de Ciencias Sociales, Niñez y Juventud, 13(2), 823-835.

França, O. (2012). Manual de Psicoética: ética para psicólogos y psiquiatras. Montevideo: Desclée de Brouwer.

García, O. (2009). El concepto de poder y su interpretación desde la perspectiva del poder en las organizaciones. Estudios Gerenciales, 25(110), 63-83.

Grossetti, M. (2014). ¿De dónde vienen las relaciones sociales? Un estudio de las redes personales en el área de Toulouse (Francia). Redes Revista Hispana para el Análisis de Redes Sociales, 25(1), 1-18.

Herrera, M. (2000). La relación social como categoría de las ciencias sociales. Revista Española de Investigaciones Sociológicas, (90), 37-77.

Jaramillo, C., Arias, A., Arias, M., Restrepo, F., \& Ruiz, D. (2012). Relaciones Sociales entre jóvenes universitarios: una mirada desde las lógicas subjetivas. Medellín, Colombia: Institución Universitario de Envigado.

Jiménez, Y. (2013). La construcción social del statu quo en la Universidad Nacional de México (1910-1914). Cultura y representaciones sociales, (15), 43-72.

Labourdette, S. (2005). Secreto y poder en la vida social. Orientación y sociedad, (5), 1-25.

Labourdette, S. (2007). Relaciones sociales y poder. Orientación y sociedad, (7). Recuperado de http://www.scielo.org. ar/scielo.php?script=sci_arttext\&pi$\mathrm{d}=\mathrm{S} 185188932007000100002$

Martínez, C., Paterna, C., Rosa., A., \& Angosto, J. (2000). El principio de jerarquía social como explicación del prejuicio y el rechazo a la acción positiva. Psicología Política, (21), 55-71.

Martín, M. (2002). La tiranía de la apariencia en la sociedad de las representaciones. Revista Latina de Comunicación Social, (50). Recuperado de http://www.ull.es/ publicaciones/latina/2002/latina50mayo/5005mllaguno.htm

Meliá, J., Oliver, A., \& Tomás, J. (1993). El poder en las organizaciones y su medición. El cuestionario de poder formal e informal. Revista Latinoamericana de Psicología, 25(2), 139-155.

Mieles, M., Tonon, G., \& Alvarado, S. (2012). Investigación cualitativa: el análisis temático para el tratamiento de la información desde el enfoque de la fenomenología social. Universitas humanística, 74, 195-225.

Montbrun, A. (2010). Notas para una revisión crítica del concepto de "poder". Polis (Santiago), 9(25), 367-389.

Montero, M. (2010). Fortalecimiento de la ciudadanía y transformación social: Área de Encuentro entre la psicología política y la psicología comunitaria. Psykhe (Santiago), 19(2), 51-63.

Moreno, H. (2006). Bourdieu, Foucault y el poder. Iberóforum. Revista de Ciencias Sociales de la Universidad Iberoamericana, 1(2), 1-14.

Moyano, A. (2014). Relaciones sociales en las organizaciones: Relaciones sociales en contextos organizacionales (Tesis de pregrado). Universidad del Rosario, Bogotá, Colombia.

Múnera, L. (2005). Poder (Trayectorias teóricas de un concepto). Colombia Internacional, 62, 32-49.

Murcia, N. (2008). Jóvenes universitarios y universitarias: una condición de visibilidad aparente en Colombia. Revista 
Latinoamericana de Ciencias Sociales, $\mathrm{Ni}$ ñez y Juventud, 6(2), 821-852.

Penaglia, F. (2012). La paradoja del poder: ¿elitización o empoderamiento colectivo? Polis (Santiago), 11(32), 105-118.

Pérez, C. (2002). Sobre la metodología cualitativa. Revista Española de Salud Pública, 5(76), 373-380.

Piedra, N. (2004). Relaciones de poder: leyendo a Foucault. Desde la perspectiva de género. Revista de Ciencias Sociales, 4(106), 123-141.

PNUD. (2004). Informe de Desarrollo Humano en Chile, El Poder: ¿para qué y para quién? Programa de Naciones Unidas para el Desarrollo, Santiago de Chile.

Rojas, I. (2011). Hermenéutica para las técnicas cualitativas de investigación en ciencias sociales: una propuesta. Espacios Públicos, 14(31), 176-189.

Santillana, A. (2005). El poder y sus expresiones. Andamios Revista de Investigación Social, 1(2), 227-239.
Serrano, I., \& López, G. (1994). Una perspectiva diferente del poder y el cambio social para la psicología social-comunitaria. En M. Montero (Coord.), Psicología social comunitaria (167-210). Guadalajara: Universidad de Guadalajara.

Solano, R. (2010). Constitución y configuración de la subjetividad en jóvenes en el contexto universitario en la ciudad de Cali (Tesis de maestría). Centro de Estudios Avanzados en Niñez y Juventud-CINDE, Manizales. Recuperado de http:// ridum.umanizales.edu.co:8080/jspui/ bitstream/6789/1177/1/Solano_Macias_ Rene_2010.pdf

Soledad, L. (2012). El ejercicio de la autoridad y las relaciones escuela-familia en la convivencia escolar. KAIROS, Revista de Temas sociales, (30), 1-16. 